\title{
Thriving In the First Semester of Graduate School: A Process of Rebalancing and Self-Determination
}

Judith Malek-Ismail

Radford University

Sheila R. Krajnik

Radford University

Follow this and additional works at: https://encompass.eku.edu/jote

Part of the Higher Education Commons, and the Occupational Therapy Commons

\section{Recommended Citation}

Malek-Ismail, J., \& Krajnik, S. R. (2018). Thriving In the First Semester of Graduate School: A Process of Rebalancing and SelfDetermination. Journal of Occupational Therapy Education, 2 (3). https://doi.org/10.26681/jote.2018.020302

This Original Research is brought to you for free and open access by Encompass. It has been accepted for inclusion in Journal of Occupational Therapy Education by an authorized editor of Encompass. For more information, please contact Linda.Sizemore@eku.edu. 


\title{
Thriving In the First Semester of Graduate School: A Process of Rebalancing and Self-Determination
}

\begin{abstract}
Beginning graduate school can be an overwhelming experience dominated by changes in roles, restructuring of routines and habits, and shift in one's balance of daily activities. The researchers employed a

phenomenological design to explore perceptions of this experience among 33 graduate students during their first semester of a full-time entry-level Master of Occupational Therapy program. One overarching theme, turbulence and rebalancing, and four superordinate themes emerged: (I) anxiety, (II) contextual stress, (III) social supports, and (IV) self-determination. The stages the participants appeared to go through were cyclical in nature, where students experienced a recurring movement of turbulence and rebalancing, progression and regression, as they moved from undergraduate to graduate education. Across themes, the concept of selfmanagement techniques and re-balancing was used by each participant to move to the next theme, or stage. Self-determination helped the participants rebalance and move through an apparent cycle away from stress and anxiety; yet social, environmental, and faculty barriers steered the students back to stress and anxiety, necessitating the cyclical movement. Maslow's hierarchy of needs was applied as a means to understand the barriers and facilitators as students' transitioned into graduate level education. Recommendations are made for how graduate faculty might facilitate adaptation during the early months of graduate school and throughout, to promote students' academic and subsequent professional success. Graduate level faculty can access varied approaches to facilitate students recognizing their own needs, satisfying them, and achieving a healthier experience during graduate education. This in turn may improve graduate student retention and matriculation.
\end{abstract}

Keywords

Occupational therapy education, Maslow's hierarchy

\section{Creative Commons License} (ब) (1) $\Theta$

This work is licensed under a Creative Commons Attribution-Noncommercial-No Derivative Works 4.0 License. 


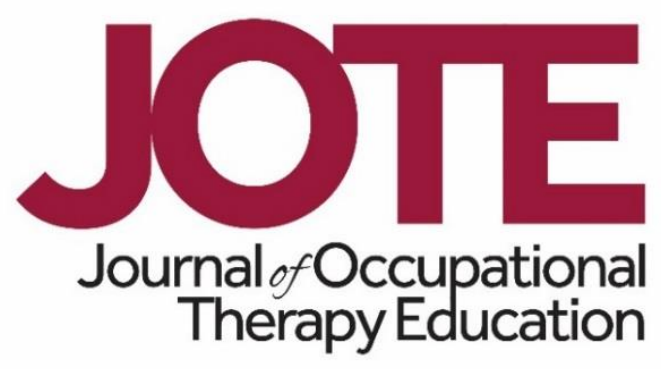

Volume 2, Issue 3

Thriving In the First Semester of Graduate School:

A Process of Rebalancing and Self-Determination

Judith Malek-Ismail, MEd, DHSc, OTR/L and Sheila R. Krajnik, EdD, OTR/L

Radford University

United States

\begin{abstract}
Beginning graduate school can be an overwhelming experience dominated by changes in roles, restructuring of routines and habits, and shift in one's balance of daily activities. The researchers employed a phenomenological design to explore perceptions of this experience among 33 graduate students during their first semester of a full-time entry-level Master of Occupational Therapy program. One overarching theme, turbulence and rebalancing, and four superordinate themes emerged: (I) anxiety, (II) contextual stress, (III) social supports, and (IV) self-determination. The stages the participants appeared to go through were cyclical in nature, where students experienced a recurring movement of turbulence and rebalancing, progression and regression, as they moved from undergraduate to graduate education. Across themes, the concept of self-management techniques and re-balancing was used by each participant to move to the next theme, or stage. Self-determination helped the participants rebalance and move through an apparent cycle away from stress and anxiety; yet social, environmental, and faculty barriers steered the students back to stress and anxiety, necessitating the cyclical movement. Maslow's hierarchy of needs was applied as a means to understand the barriers and facilitators as students' transitioned into graduate level education. Recommendations are made for how graduate faculty might facilitate adaptation during the early months of graduate school and throughout, to promote students' academic and subsequent professional success. Graduate level faculty can access varied approaches to facilitate students recognizing their own needs, satisfying them, and achieving a healthier experience during graduate education. This in turn may improve graduate student retention and matriculation.
\end{abstract}

\title{
INTRODUCTION
}

\section{Graduate Education as a Time of High Stress}

The demands of graduate education are well documented and include intense academic workloads with frequent examinations in a context of challenging personal and social transitions (Evans, Bira, Gastelum, Weiss, \& Vanderford, 2018; Ewles, 
Sorenson, \& Sasso, 2016). Graduate school has been known by students and educators alike to be a stressful time, often provoking serious changes in mental health (Evans et al., 2018; Pfeifer, Kranz, \& Scoggin, 2008; Wang, 2015). Publications discussing issues in higher education increasingly report graduate student depression, anxiety, emotional distress, and related retention problems. Thirty to fifty percent of students are reported to leave graduate programs, while nearly half consider leaving, most frequently citing the emotional toll (Stubbs, Pyhältö, \& Lonka, 2012). Indeed, the journey into and through graduate school has been described in the literature as perilous (Weidman, Twale, \& Stein, 2001) and likened to a shark tank due to the social, intellectual, and mental demands (Benton, 2003).

Being in graduate school has been characterized as an overwhelming experience dominated by a change in roles, a restructuring of routines and habits, and a shift in work-life balance (Evans et al., 2018; Pfeifer et al., 2008). In their 2014 study of graduate student well-being, Panger, Tryon, and Smith found that $47 \%$ of Ph.D. students reported depressive symptoms. Results from a 2017 study mirrored those findings, with $51 \%$ of graduate students reporting two symptoms of mental health problems, while 32\% reported four or more (Levecque, Anseel, De Beuckelaer, Vander der Heyden, \& Gisle, 2017). Increased stressors in graduate school were found to be highly related to poorer mental health (Evans et al., 2018; Jahan, Siddiqui, Mitwally, Al Zubidi, \& Al Zubidi, 2016).

Sources of stress appear to stem from the institutional level, interpersonal/intrapersonal level, and logistics, such as financial stressors. Institution based stressors encompass a tradition of expectations that graduate education is only for the toughest of individuals, and its intent is to socialize and toughen students for the real world (Patel, 2015; Weidman et al., 2001). Issues of power differentials, graduate work supervisory processes, and performance evaluation systems have been reported as problematic among graduate students (Ewles et al., 2016; Jahan et al., 2016; Levecque et al., 2017; Weidman et al., 2001). Interpersonal and intrapersonal needs resulting in feelings of stress and anxiety surround concerns over ability to learn and perform at graduate level expectations, relationships with peers and faculty, high workload, and lack of balance between school work and non-school life (Jahan et al., 2016; Levecque et al., 2017). Insecurity about the financial demands of graduate education and job outlook upon graduation added to aforementioned stressors.

Preparing students to enter careers as health professionals has been an increasing trend in graduate education (Okahana \& Zhou, 2017; Seegmiller, Nasypany, Kahanov, Seegmiller, \& Baker, 2015). Changes in credentialing requirements from an associate's or bachelor's degrees to master's or doctorate level have meant advanced degrees for many health professions, such as occupational and physical therapy (American Occupational Therapy Association, 2011; Commission on Accreditation in Physical Therapy Education, 2011). Graduate professional degree programs tend to be long and intense, with full-time year-round heavy semester credit loads, for three or more years (Seegmiller et al., 2015). Occupational therapy (OT) is an example of this trend, and the reported stress of OT students matches that of the aforementioned literature. Pfeifer, 
Kranz, and Scoggin (2008) reported that nearly $67 \%$ of students surveyed in a graduate OT program rated their stress as "above average" to "highest in my life."

\section{Maslow's Hierarchy of Needs in Higher Education}

A lens through which to view the concerns and stressors of graduate students is Abraham Maslow's hierarchy of needs (1954). Maslow's hierarchy has been applied to students in higher education as a means to understand their learning barriers and facilitators (Freitas \& Leonard, 2011; Gobin, Teeroovengadum, Becceea, \& Teeroovengadum, 2012; Holdford \& Lovelace-Elmore, 2001). Maslow (1954) proposed that human needs serve as motivators to seek gratification, and basic, lower level physiological, safety and security, and love and belonging needs must be met before an individual can focus on meeting higher order needs that pertain to personal growth, including mastery for self-esteem, and self-actualization. These unmet needs become regarded as stressors leading to anxiety, and potential threats to mental well-being, particularly when a person is challenged to meet these needs over longer periods of time (Bulut, Hisar, \& Demir, 2010; Noltemeyer, Bush, Patton, \& Bergen, 2012). Furthermore, unmet physiological and security needs are barriers to the learning processes that are inherent in the higher level needs that lead to mastery and selfactualization (Holdford \& Lovelace-Elmore, 2001).

When applied to students in higher education, physiological needs pertain to nutrition, either obtaining food or preparing meals; personal health - mental and physical; having adequate housing and sufficient sleep, and balance in necessary daily life roles and activities (Freitas \& Leonard, 2011; Holdford \& Lovelace-Elmore, 2001). Needs related to safety and security include the experience of safety in one's surroundings on and off campus,; financial security for room, board, and tuition; and psychological factors surrounding academic failure, fear of judgement, or psychological or intellectual inadequacy for program demands. For a segment of graduate students, physiological and safety needs involve providing for others, such as a spouse or children. For graduate students, love and belonging needs are comprised of faculty and peer relationships; personal relationships with a partner, friends, or family; and belonging to and feelings of acceptance into like-minded groups (Gobin et al., 2012; Holdford \& Lovelace-Elmore, 2001). The fourth level of Maslow's hierarchy is esteem needs, or the need for mastery over a student's chosen endeavors, confidence in the ability to succeed, and a sense of accomplishment and recognition or admiration (Bulut et al., 2010; Gobin et al., 2012). Self-actualization as the highest level of need is associated with attaining a sense of fulfilling one's potential for complex knowledge and deep personal satisfaction, combined with contributing to the needs of the larger society (Freitas \& Leonard, 2011; Gobin et al., 2012; Holdford \& Lovelace-Elmore, 2001).

\section{Study Purpose}

Due to the evident stressors of graduate students affecting mental health, and thus learning, it becomes imperative to acknowledge and understand the transition process into and through graduate school since a healthy balance in life roles and daily activities is vital to human health and well-being (Dickie, 2009). Examples of life roles, patterns, and routines include activities of daily living, care of others, educational activities, work, 
sleep and rest, and leisure or play. Human occupations, or daily activities, are typically organized around habitual routines or patterns of activity, and clustered within the roles that a person may assume in life. Common life roles for graduate students are learner, peer, friend, daughter or son, worker, and volunteer. Less commonly held roles for graduate students include parent, spouse, caregiver for an aging parent, and professional. Greater knowledge of graduate students' needs could lead to a better understanding of how faculty and administration might best help these students achieve and maintain balance in their lives and manage stress during this transition (Oswalt \& Riddock, 2007; Pfeifer et al., 2008). In order for this understanding to occur, the meanings that the experience of transition and occupational change has for students as they enter and move through a graduate education program must first be discovered.

The objective of the current phenomenological study was to gain this understanding by exploring how first-year Master of Occupational Therapy (MOT) students identified changes in their occupations, roles, habits, and routines, and what strategies they used to adapt to these changes since beginning graduate school. Using Maslow's framework, insights were sought into what student needs emerged during the transition into graduate education, and how these needs were being met by the students themselves and by faculty. Knowledge gained was then used to make recommendations for how graduate faculty might facilitate adaptation during the early months of graduate school and throughout, as a means to promote students' academic and subsequent professional success.

\section{METHODS}

\section{Study Design}

The researchers employed a phenomenological qualitative design to explore perceptions of graduate students enrolled in the first semester of a traditional, full-time entry-level MOT program at a rural public university in southwest Virginia. A phenomenological research design is concerned with the specific ways in which individuals consciously reflect on and construct meaning of their experiences (Creswell \& Creswell, 2017). The researchers selected this design to capture the participants' words and stories that revealed their perceptions during their first semester of a graduate healthcare program, thus allowing the researchers to understand how each participant experienced the transition from undergraduate to graduate education, and providing insights into the roles of faculty in this transition, as perceived by the participants. Second-year MOT students were engaged as student researchers for conducting and transcribing interviews.

\section{Recruitment Procedures}

Following approval by the university's institutional review board (IRB) potential participants were introduced to the purpose of the study by an OT instructor who had no involvement in the research protocol. Participants were recruited in October 2015 and again in October 2016 from graduate students in their first semester of the MOT program. Students who wished to participate signed an interest form, and were then randomly assigned to a pair of second-year MOT student researchers by the faculty 
researchers. The potential participants were contacted via email or phone by one of the student researchers, informed of the purpose and method of the study, and asked to participate in a one-hour individual, semi-structured audio recorded interview, with a potential second 20-30 minute meeting for member checking.

\section{Participants}

Participants came from two MOT student cohorts, in order to have a sufficient sample size for enhanced study validity. The participants were four men and 29 women, who were in the latter half of their first semester of the MOT program. The participants were Caucasian, under the age of 35 years old, in graduate school for the first time, and were from within the state or adjacent surrounding states. No significant programmatic changes occurred in the MOT curriculum, faculty, or department operations during the two-year study timeframe; thus first-year student experiences were equivalent from the institutional perspective.

\section{Data Collection}

Two faculty researchers supervised all of the procedural aspects of the study and provided training and ongoing guidance to the second-year MOT student researchers across the two year study. Two cohorts of MOT student researchers participated in the study; one cohort in 2015 and another in 2016. Each pair of student researchers contacted an assigned participant and made arrangements to meet in a private space on campus. During this meeting each participant gave written informed consent to be interviewed and audio recorded. Participants were explicitly informed that a) their choice to be involved in the study or not would not affect their grades in any MOT course; b) all data would be de-identified, their names would not be attached to the transcripts, be known to the faculty researchers, or be used in any way; c) all responses would be kept strictly confidential and student researchers had signed confidentiality agreements; $d$ ) they could withdraw from the study at any time without repercussions; and e) their transcribed interview would be kept password protected for three years per IRB requirements, then permanently deleted.

The data were collected through audio-recorded face-to-face interviews after the student researchers underwent training in qualitative methods, including interviewing techniques. The student researchers used a semi-structured interview guide that they developed and piloted with guidance from the faculty researchers. The faculty researchers provided a critical review of the interview guide to ensure the questions were not leading the participants' responses. Interviews were guided by broad, overarching, general questions, with set prompts to cue the student researchers to ask probing questions about the participants' initial responses to seek depth of understanding about perceptions and meaning of their experiences with daily life balance or imbalance since beginning the graduate program. Participants were asked to describe their experiences with and perceptions of transitioning to a full-time MOT program, the changes in their occupations, roles, habits and routines, and how they have coped since beginning graduate school (see Table 1). 
Participants were informed during the consent process, and again before each interview, that they could request rest breaks, and were free to withdraw from the study at any time, for any reason. The student researchers were trained in therapeutic use of self and instructed by the faculty researchers that they were allowed to provide immediate assistance to participants that displayed signs of anxiety, however they were instructed that participants should be referred to the Counseling Center at the university in the event that anxiety existed before the interview.

Table 1

Interview Questions

Overarching Questions:

Can you describe your experiences with daily routines from before you began

graduate school to now that you are in the full-time MOT program?

What are some of the activities/occupations that you may or may not have

experienced change in since becoming a full-time graduate student?

How would you describe your lifestyle balance?

Tell me about any new ways that you are using to balance your occupations and deal

with this new situation.

Examples of follow up and probing questions:

How have your daily routines changed since starting in the MOT program?

What supports do you have to help you through this occupational change?

How well do you think you are coping?

Describe the most difficult aspects to deal with related to the changes you've made.

Describe the pleasurable aspects of the changes.

\section{Data Analysis}

Each participant was assigned a random initial and pseudonym as an identifier, and the transcripts and field notes did not contain the name of any participant. Interviews were transcribed verbatim by the student researchers using password protected campus computers and stored on the secured university server. Each written transcript was approximately 25 pages long.

Coding. Data analysis was initiated by the student researchers working in teams of four, using manual in vivo coding to organize the initial data for two transcripts per team. This procedure was repeated for the second year of the study.

The faculty researchers independently reviewed and analyzed the transcripts and completed the final coding and analysis at the end of the second year of the study. The researchers independently looked for emergent themes and used emotion coding, a method of coding that labels the emotions experienced by the participant to explore intrapersonal and interpersonal experiences and actions (Saldana, 2016), and contextual procedures to analyze the data. After agreeing on initial 'emotion codes', the researchers further reduced the data by grouping similar codes based on contextual features as they related to Maslow's hierarchy of needs (1954). Emotion and contextual 
coding helped the researchers assign a label to the context in which the participants experienced certain emotions, thoughts, and feelings (identified by meaningful words and statements).

A variety of techniques were employed by the researchers to ensure the trustworthiness of the study findings and conclusions. The researchers recognized that they had a combined 20 years of experience teaching at the graduate level, and used data comparisons to literature and reflexive journaling that recorded thoughts, assumptions, and beliefs during data analysis to reduce researcher bias. The researchers used a reflexive approach during data analysis. After agreeing on initial codes, the researchers transformed a directory of codes into a matrix to organize them into categories. Analytic memos and reflective notes were added that represented themes, and allowed for comparison among themes in the same category and between categories (Maxwell, 2005). Using triangulation to ensure trustworthiness, the researchers coded independently, and then confirmed findings during data analysis, achieving $100 \%$ agreement of similarity in codes, text passages, themes and final categories to ensure intercoder reliability. All of the analysis documentation from the study was maintained and stored to ensure transferability of findings to future studies.

\section{RESULTS}

Many factors contributed to how the participants perceived and managed the transition into graduate school. The experiences in the first semester of graduate school were similar for each participant in this study. One overarching theme, turbulence and rebalancing, and four superordinate themes emerged from this study: (I) anxiety, (II) contextual stress, (III) social supports, and (IV) self-determination. Each theme represents barriers and facilitators that influenced the perceptions of the first semester of graduate school for these participants. The themes depict a cycle of adjustment during each theme, or stage of transition, and not a true hierarchy (see Figure 1); thus, the resulting themes are not presented in direct alignment with Maslow's hierarchy of needs (1954). The researchers also wanted to remain true to the narratives as stated in the participants' words, therefore used Maslow's theory to later understand how faculty might respond to students' perceived needs. In each theme the concept of selfmanagement techniques and re-balancing was found to be used by each participant to move to the next theme, or stage. Self-determination in many forms helped the participants rebalance and move through an apparent cycle away from stress and anxiety, yet social, environmental, and faculty barriers steered the students back to stress and anxiety, necessitating the cyclical movement once again. 


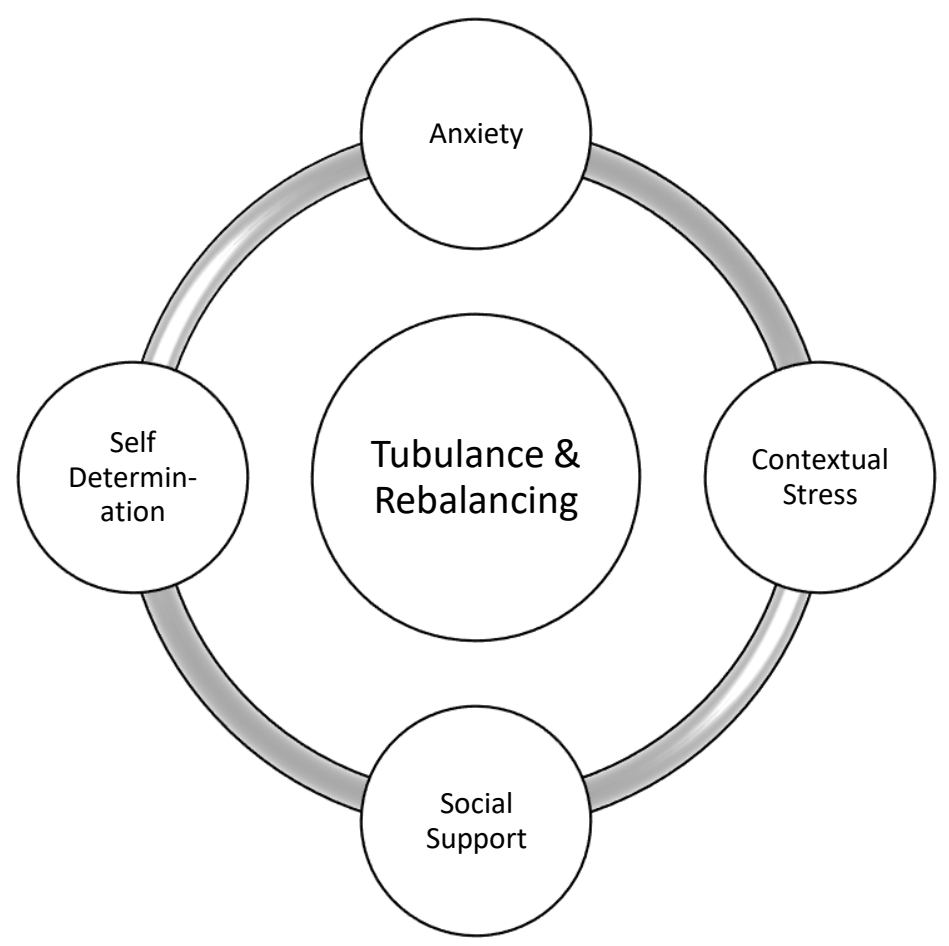

Figure 1. Overarching theme and four superordinate themes.

\section{Overarching Theme}

Turbulence and rebalancing. Life imbalance was high in the beginning of the first semester of graduate school. The narratives from the participants illustrated a continuous cycle of occupational imbalance and rebalancing during this semester. This cycle of turbulence and stress was fueled by persistent anxiety, loneliness and feelings of apprehension, and worry over course assignments, personal and faculty expectations, and grades. All of the participants were at heightened arousal to not forget important course details or assignments. Most stated they felt they had to be doing something for school all of the time, resulting in a great deal of anxiety. The students perceived graduate school to be difficult, reporting high amounts of work and more time spent completing assignments compared to their time as undergraduates. They expressed that there were many changes at once to get used to, with no time for selfmaintenance or leisure. One female participant revealed that the first semester caused her mental anguish, stating, I feel like this is kind of dramatic, but I feel like in the beginning it really changed my personality for a little while cause I was just like, I was never really someone who was really worked up or like on edge, but I was like always on edge in the beginning [of the semester].

Several participants reported they were aware of when their school performance and personal lives were affected by anxiety. The researchers discovered through participants' stories that some of the students were able to use self-management 
techniques and early adaptation to calm anxiety and temporarily break the cycle of emotional turbulence to facilitate better academic performance, however feelings of stress and anxiety were apparent when self-management techniques were not utilized.

\section{Theme I}

Anxiety early- semester. Anxiety can help or hinder performance, however in most instances mental stress will affect physical and mental health, and most importantly learning (Bastable \& Dart, 2011). Several of the participants reported changes in their mental state early in the semester, with increased forgetfulness or other mental and physical responses to the stress. One student described how her mental status changed:

I feel like my brain is just going chaotic right now because there are so many things to remember. I'm always on my toes I guess you could say and l've been more forgetful lately just because there's just so much going...

Anxiety may have affected normal sleep patterns. Some students reported sleep deprivation, or difficulty falling and staying asleep. Other students reported they slept better now, and had no problems falling asleep, due to fatigue from the high workload in school. Sleep seemed to take on greater importance as participants transitioned into the midst of the first semester.

Feelings of uncertainty and fear of the unknown were found threaded throughout the narratives of the female participants. Personal safety was brought up during most of the interviews. Some of the female students reported that they were new to the area, and the unfamiliar surroundings of the university 'didn't feel like home' yet. These students were not comfortable going outside their apartment in an unfamiliar area, or they moved into an apartment with people they did not know, and tended to stay indoors after school, and spend time alone.

There was also decreased time for meaningful leisure pursuits and to engage in meaningful life roles. Married students reported they had less time to shop for groceries, prepare meals, and clean. The students longed for more time for relaxation and leisure. Most of the students were frustrated with time demands, and felt forced to give up valued activities, especially exercise and leisure, for school work. In general the participants reported they had less time for exercise, and that it was difficult to fit a workout into their daily routine. The students reported that they experienced lack of time for self-reflection, and they felt they 'couldn't risk' taking time for leisure or social activities, because they 'feared falling behind' in class, or 'felt guilty' taking time for leisure. One participant just wanted to be alone and to relax, she stated, "My idea of fun is now a moment of alone time, if you have a minute to yourself it's just like ahh, this is just the best thing ever." Other students reported that they did not have enough "me time', or were constantly thinking about school work. One participant was more dramatic, and she simply stated, "my life is over." 
Basic rebalancing early- semester. The participants described how they were able to take concrete action steps at the basic level to rebalance. The researchers found that the students became intentional about getting enough rest or sleep. Most students reported that rest and sleep were key to being able to cope with the demands of graduate school. The students stated that they found time for leisure and rest, or that they intentionally made time for rest whether they had time or not. One of the participants pointed out the importance of sleep for her, stating, "if I'm studying for a test and I'm just exhausted, I know it's better to go to sleep and get the rest than stay up and try and study."

The faculty may have contributed to some of this early rebalancing. Connection with faculty may be easier in a small program when there is a smaller cohort of students. Most of the participants had a positive perception of the MOT program faculty during the beginning of the semester. They viewed the professors as 'helpful' and 'being on their side', and more caring than the professors in undergraduate school. Other students reported that it was easier to accept the workload because the faculty gave a clear expectation early on about the demands of graduate school. One student reported that after self-reflection he was able to put everything into perspective, and "graduate school was not the end of the world." Most of the students projected into the future as a way to cope. They told themselves that graduate school was a 'stepping stone' to the future, that it was 'not forever', and that it was "okay to sacrifice now to get where I want to be in the future." In general, the participants had an awareness of the need for time management skills. Some of the participants began to use a detailed schedule to maintain balance with self-care and graduate school work. They attempted to balance home making chores, exercise, homework, and leisure activities across the week, instead of trying to fit everything into their daily routine.

\section{Theme II}

Contextual stress early-mid semester. The researchers found that faculty expectations were viewed as one of the main sources of insecurity toward the middle of the first semester. From the narratives it appeared that the participants had an incomplete knowledge of what the field they were studying, occupational therapy, fully encompassed, and lacked recognition of the scope of learning a new discipline. The students were frustrated at the amount of time they 'sacrificed' for school work. The pacing of instruction increased stress as the course expectations increased. Participants expressed a fear of falling behind, and trying to keep up with readings and assignments. They reported that the first few weeks of graduate school were very worrisome. Several students stated that seeing the syllabi on the first day of classes was overwhelming, and the high workload caused increased anxiety and stress, especially when multiple assignments or tests were due in the same week. The students felt that the faculty intentionally planned for many assignments to be due at the same time. One of the participants felt that the demands in the MOT program went against what was being taught about occupational balance and health. She stated, I personally think it's too much, we talk about tempo and time and temporality a whole bunch, but in terms of what we're actually doing here I feel like it's kinda contradictory to 
what we learn so I feel like a lot of stuff that we're doing is coming at us like way too quick and some things are all over the place and some things we have talked about in class and some things we don't that we have quizzes on ...

Several narratives revealed negative self-talk from the participants, and two of the students reported, "I'm not going to be able to do this [school], I called my parents almost three times a day stressing about it", and "if I don't do this [pass the class] I'm gonna fail, and if I fail then I am going to be unsuccessful and I have wasted all my time."

Home and family relationships were important to the participants. The students enrolled at this particular university because it was close enough for them to go home on weekends to visit parents and siblings. Many students reported going home frequently during the first few months of the first semester. They reported feeling homesick, lonely, sad and isolated at times, and they missed their family and old friends from home. A couple of the students described going home as a vacation "where I do nothing", or "just spend time with them [family] and not worry about the demands of school." It appeared from the participant's statements that parents were viewed as a main support system; one student reported the following, My parents are definitely like, another support system that I value, because they're always able to answer my phone calls, or offer me words of encouragement when l'm not feeling ok about like a certain class or, assignments.

Contextual rebalancing mid-semester. During mid-semester the participants entered a phase of contextual rebalancing, expressing that they perhaps had worked themselves up into thinking that graduate school would be extremely difficult, and really it wasn't that bad after all. Temporary life imbalance seemed acceptable if the individual finds meaning in the imbalance, and perceives it as positive instead of negative. For example, one student reported that she was pleased with herself and her occupational balance now that she was in grad school compared to when she didn't have a career goal, she revealed, "I was slightly unhappy when I was in the work cycle and I didn't really have any meaning or value to the occupations that I did, now the imbalance [of school life] is meaningful." For other students the excitement of 'just being accepted' into the program decreased their anxiety. One student described how she was in the honeymoon phase,

It really hasn't been as overwhelming as I thought it would be. I think because I'm still just so excited to be here. It was such a long process to get in and this is where I wanted to be and right now I'm still in the honeymoon phase. Like ooh this is so cool umm which hopefully I think will last throughout the program.

The participants developed new habits and routines to manage the stress of the graduate school workload. They used self-regulation strategies as stress reduction and a facilitator of feelings of security. Some students moved from the use of broad schedules for time management, to using detailed schedules to plan precise blocks of time and manage anxiety, yet others avoided looking too far ahead to prevent further anxiety. The students reported becoming more aware of their ability to manage stress 
and avoid feelings of being overwhelmed. They reported using or were learning to use self-regulation strategies for anxiety and worry to keep them uplifted. The most common reported strategies were walking, alone time, crafts, and exercise. Other students used spiritual practices and religion to help them get through missing family and managing school stress. These students used methods such as prayer to a higher power to get through hard times in school, or going to church, journaling, and Bible reading. Finally, positive self-talk was noted by some of the students at this stage, and they used statements such as, "Grad school is a 24/7 job", "It's still going to be ok if you don't do as well as you wanted; life continues even in grad school", "I'm where I want to be", and "I've decided to enjoy the positive times" to describe their feelings and perceptions.

\section{Theme III}

Social supports. Some of the participants longed for the comfort and intimacy of old friends. The students reported they had no social life because they didn't know anyone in the area, or that they had no time to see old friends, and they had no local social support systems. One of the participants missed social belonging, and stated that building relationships with people was meaningful to her, stating, It's like probably my favorite like thing [being with people] to do outside of work and school, but I don't really have time for that anymore. So there's been a loss of like meaningful occupation.

Most participant narratives revealed social transitions, and a loss of interest in old patterns of behaviors. Participants reported they no longer shared the same interests or priorities as their old friends from undergrad "[where everyone is] still partying", or in the 'party mode', or who 'don't study', and therefore do not see the old friends as much as before. With this transition came an awareness that it would take time to adjust to new social patterns, and to form and maintain new relationships. Time spent with family or friends was pre-planned, and students described that they made efforts to see them. They used virtual strategies such as texting, social media, and the phone to stay connected to family and friends. These forms of virtual connecting were considered quality time.

For others, security, and a sense of belonging and social connectedness were linked to geographic context. Many of the participants purposely applied to the university because it was a small school, yet several of them found the "school to be too small". They were not prepared for how hard it would be not to have more people around and to live in a rural community. One participant expressed her feelings this way, It's so hard being around like in a smaller school like l'm used to seeing so many people all the time and like you walk across campus during a class change and there's like twenty people (laughs) as you pass on the sidewalk and that's it.

Other students liked the smaller community and university compared with a feeling of "drowning in people at a larger university." 
New social supports and belonging. Only a few of the participants felt that their cohort of classmates was an additional stressor. These students reported that excessive worrying and stressing over class work was contagious, and that group work was a distractor, causing them to isolate themselves and work alone. The majority of the participants reported that their roommates, who were often in the same graduate program, and classmates were their main social network, and form of social support. The students found security by being with others who shared the same experiences, and were going through the same transition into graduate school. They developed support systems early in the program with other students in their tabletop groups [sitting with 3-4 other students], and these were regarded as social groups. The participants emphasized that they were making new friends from spending so much time with classmates, and their new classmates became family. Studying in groups of peers was used for social support, social interaction, and security during and after class. One of the participants reported that she "couldn't wait to leave class to go study with her table group." The participants relied upon other students, especially roommates, to stay grounded and focused, and that "Roommates encourage and push one another to do school work." Roommates provided psychological support, most likely because they were going through the same transition as the participants. The participants felt supported and not alone as they developed routines with their roommates for managing life and study skills. Time spent with roommates relieved anxiety and helped the participants deal better with stress, and roommates monitored one another's health habits and encouraged balance in occupations. One participant stated, My roommates are probably the biggest support system right now just because, we're able to collaborate ideas, encourage each other to study, and um (pause) we do readings together sometimes, or, we'll go on campus to study together and um be productive.

\section{Theme IV}

Self-determination. The narratives revealed that the students demonstrated internal motivation, self-determination and emotional maturity toward the end of the semester. The students wished to have control in graduate school. They were motivated by external rewards such as grades, social acceptance from their classmates and relationships with their instructors. Graduate school and a career in OT was a personal choice for each participant, and they had self- satisfaction with their major and the university experience. Internal motivation was seen as the students accepted responsibility for their actions and potential academic failures, and appeared to transition from striving for academic perfection, to a realism that they could still be successful in graduate school with self- perceived shortcomings. Some of the students appeared to be able to effectively manage stress on their own, instead of relying upon parents for emotional support. In general the students transitioned from having a 'lack of control' or 'feeling incompetent', to finding satisfaction and enjoyment in graduate school. The narratives revealed that participants were future oriented, and they used goal setting to stay focused on the end goal of a career in OT, and also as a coping strategy. All of the participants found value and meaning in graduate school, and they had a desire to do well in the MOT program. Even though graduate school was 
stressful, the participants demonstrated intrinsic motivation and perceived school as valuable and worth their time and effort. Toward the end of the semester they saw the value in the course workloads and expectations. The students used statements such as, "this is good stress", "the workload is stressful but like you're getting somewhere so it makes it worth it", and "I study now to understand, it's not about the grade."

The participants perceived the material to be relevant compared with undergraduate content that was perceived as a lot of times to be 'pointless', with content that was 'filler or fluff, for example, "so [in undergrad] I would just um you know, learn it and forget it all, but now everything that I'm learning l'm trying to remember." Most of the participants gave detailed examples of their habits and routines from undergraduate school. The participants reported that there was more time to waste in undergraduate school, and that "[undergrad] school wasn't number one." The students highlighted several poor study habits, such as reading the night before class, or not reading at all. Or they crammed for exams, and spent less time on school so that they could 'hang out with friends', or to 'just waste time' watching 'Netflix'. A few of the participants reported that they came into graduate school with good study habits, however all of the participants reported that they restructured their study habits and routines to become more efficient and productive so they could keep up with the demands of the graduate program. New study habits included the use of daily planners, reviewing the course syllabi every day to keep on track, and not procrastinating. Some participants used creative forms of multitasking and studied while they were working out at the gym. Overall, as the semester progressed, the participants were willing to sacrifice leisure time and social activities to focus on graduate school. They had an increased awareness of new demands on time, and the need to improve time management skills for an important goal. They also recognized that their new study habits were paying off.

Overall the participants viewed themselves as adults instead of a 'just a college kid. They spoke of how they were now more focused toward their career, and were satisfied with graduate school because the education will allow them to 'become something' in the future. A few of the participants stated the following, "nothing else matters except school", "the preparation is paying off", and "at the end of the day this is the most important thing, and this is what is going to help me reach my goal."

\section{DISCUSSION}

The purpose of this study was to gain a deeper understanding of graduate OT student perceptions of changes in their life patterns, routines, and needs, as well as the coping strategies students used to meet identified needs as they moved through the first semester of a full time graduate program. Knowledge was gained about what needs surfaced during the transition into graduate education, and how students perceived these needs were being met by the students themselves and by faculty. While the resulting themes do not appear to align in a temporal hierarchy as does Maslow's theory of needs (1954), the needs identified by the student participants nonetheless connect directly with the categories in Maslow's theory. 


\section{Graduate Student Needs Based on Maslow's Hierarchy}

Participants indicated numerous physiological needs that surfaced early in their transition into graduate school, including concerns with housing, sleep, lack of time for grocery shopping or meal preparation, and overall imbalance in important daily life activities. These needs are in line with those identified in the literature on graduate student stress by Freitas and Leonard (2011), Gobin et al. (2012), and Bulut et al. (2010). Likewise, needs related to security that surfaced in the present study are congruent with those discussed by these same authors, including financial, psychological, and emotional security. Personal safety, whether physical or virtual, was not raised as a concern in the present study, and is less commented on in the literature as well, indicating that this may be less of a need for graduate students. Social interaction, or Maslow's love and belonging need, was shown to be a significant area for study participants; they reported longing for time with family and old friends, and many put forth immediate effort at building new relationships particularly with roommates or peers in the same graduate program. While not a factor in the present study of oncampus participants, social interaction needs of e-learning students were perhaps a higher priority than physiological needs (Bishop, 2016), lending support to the relative importance of acknowledging and facilitating graduate students' love and belonging need satisfaction. Interestingly, Gobin et al. found a high need of students for acceptance from faculty, which was not apparent in the current study, perhaps due to the earlier timing of the interviews coming when students are still looking more to parents or familiar relationships for validation, and less to graduate level peers and faculty.

Esteem needs identified by participants in this study are again similar to those discussed by other researchers (Bulut et al., 2010; Freitas \& Leonard; 2011; Gobin et al., 2012): mastery and development of self-confidence in graduate level coursework, self-respect and respect from peers and faculty, and more autonomy for problemsolving and decision making. It is at this stage of need satisfaction that a shift was apparent where participants were recognizing their inner capacities to self-regulate their stress and anxieties through coping and adaptive strategies, and thus intentionally employ their chosen strategies directed at self-determination, indicating more internal motivations for success (Bulut et al., 2010). It is the researchers' experience that at times graduate students do not make it to this level; they remain overly stressed, and they express lack of support from the program faculty or administration, hence getting stuck in themes I and II, and not developing the necessary internal locus of control to guide them into more self-directed stages. This is perhaps when students consider leaving or actually drop out of graduate school. Participants in the present study were not seen to be achieving the highest level of Maslow's hierarchy, self-actualization, however they indicated the desire, or need, through commenting on being focused more on actual learning than on being motivated by making high grades or passing tests, and feeling satisfied even though life patterns are unbalanced because they are engaged in meaningful pursuit of knowledge for a valued career. Similarly, Gobin et al. (2012) found that students remained at lower levels of needs but expressed the desire for selfactualization. 


\title{
IMPLICATIONS FOR OCCUPATIONAL THERAPY EDUCATORS
}

\author{
Understand the Human Experience \\ Results from this study and others referred to earlier lend support to faculty imperatives \\ to be aware of graduate students' needs at all levels and to facilitate students meeting \\ those needs. Faculty must possess a broad understanding of basic human needs and \\ the human experience, particularly the experience of daily balance, and how stress and \\ anxiety are related to imbalances in meeting those needs, or dealing with chronic unmet \\ needs. Faculty and administration should further understand that some traditional \\ approaches to graduate school very likely cultivate stress and anxiety, and lead to \\ deficient mental health and overall well-being for graduate students. What follows are \\ suggestions drawn from the student narratives in the current study, the researchers' \\ reflections on course and curricular factors already in place, and lessons learned from \\ connections made in the literature on this topic.
}

\section{Recognize Unmet Needs}

Educators should expect that lower level needs are likely present and unmet initially in graduate students, at least for a period of time, as students begin a new graduate degree program. Recognizing the presence of these basic needs can encourage educators to learn where their students are coming from, and listen intentionally to what students are feeling. This can enhance students' feelings of security, psychologically and emotionally. Clear expectations early on about the demands of a graduate program facilitate students' preparations to meet those demands, and promote positive attitudes and self-talk as coping strategies during the transitions through imbalance and rebalancing of life routines. Expectations should address temporal, financial, intellectual, and social interaction demands. Communicating these expectations can be done in a compassionate manner that takes on a positive tone of belief in student success, versus instilling a sense of fear and trepidation about what is to come during graduate school. Initial and ongoing communication with graduate students might take on a town hall meeting appearance, as this also conveys to students a sense of safety, security, and belonging. Study participants indicated that clear course expectations, both verbal and written, clear and consistent grading policies, and consistent application of policies were facilitators of stress management and anxiety self-regulation. Thus having the same policies in place across all courses in a program of study or within the university department is desirable, as opposed to variations from course to course, for example with class absences or late assignment submission.

\section{Support Social Connectedness}

Social connectedness is important to human well-being, and social relationships were consistently seen as facilitators of need attainment and movement to and through the next stage in the graduate students' cycling through turbulence and rebalancing. A cohort approach is used in the researchers' graduate program which was revealed to be a strong facilitator of social belonging, support, and achieving and maintaining life balance during stressful periods. Cohorts can be achieved in face-to-face as well as virtual environments, and may help to alleviate the isolation that is experienced by graduate students (Bishop, 2016). 


\section{Respect}

Esteem needs of the study participants were facilitated through a respectful culture within the MOT program that emphasized learning for current and future professional growth, over competition for achievement. This approach helped students maintain perspective over the perceived drive for unattainable perfection, and redirected energies toward learning in the moment, and staying mindful of the time-limited demands of graduate school. Unconditional positive regard being shown to students as they moved through the learning process also enhances esteem needs; ideas however can and should be critiqued, which can be part of the culture fostered in graduate education. Lastly, facilitating movement further into self-actualization, or an emphasis on career maturity may promote self-determination and accountability in coursework, assignments, and graduate projects or dissertations.

\section{Limitations}

It is appropriate for the qualitative researcher to conduct the single, in-depth interview as in this study, with each participant; although this method did not allow for investigation into the participants' perceptions over time. However, the purpose of the present study was to investigate students' perceptions only in the first semester of a graduate program. The faculty researchers were careful not to let personal views regarding first semester graduate student behaviors influence the data collection and the analyses processes. Yet their personal experiences and interest in how graduate students view the transition in the first semester guided the overarching research question. Formal member checking was not carried out in this study secondary to the nature of the study with second year MOT graduate students trained as researchers.

Despite these limitations, many important findings about graduate student transitions emerged from the participants' narratives. The strengths of this study include the primary researchers' knowledge of the topic. The large sample of student participants brought a richness from their first-hand accounts of experiences in their first semester of graduate school, and their willingness to share these feelings with the researchers. Looking forward, it may be appropriate to employ a broad, mixed-methods study with a larger more inclusive sample of students to investigate the views of graduate students from additional disciplines and programs across the region or nation.

\section{CONCLUSION}

The researchers in this study believe that the stages the participants appeared to go through are cyclical in nature, in that students experience a recurring movement of turbulence and rebalancing, progression and regression, as they move from undergraduate to graduate, through a graduate program, and likely again from graduate school to working in a chosen career. It is anticipated that based upon the overarching theme of turbulence and rebalancing, individuals may experience going back into lower levels on Maslow's hierarchy as they prepare to graduate. Anxiety resurfaces as students are confronted with oral examinations, and thesis or dissertation defense, or the need to pass national credentialing or boards exams. They again face financial insecurity, the need to obtain a job, uncertainty of when and where to seek employment, or where to live. It was further discovered that during the first semester graduate 
students were not immersed in the process of self-actualization, nor would this be expected, given the lower order needs identified by the study participants. They were however clearly setting themselves up for self-actualization through future-oriented thinking, goal setting, and using a vision of a fulfilling career as a coping strategy. Graduate level faculty can access varied approaches to facilitate students recognizing their own needs, satisfying them, and achieving a healthier experience during graduate education. This in turn may improve graduate student retention and matriculation.

\section{References}

American Occupational Therapy Association. (2011). Current ACOTE accreditation standards. Retrieved from http://www.aota.org/Educate/Accredit/StandardsReview.aspx

Bastable, S. B., \& Dart, M. A. (2011). Developmental stages of the learner. In S. B. Bastable, P. Gramet, K. Jacobs, \& D. L. Sopczyk (Eds.), Health professional as educator: Principles of teaching and learning (pp. 151-197). Sudbury, MA: Jones \& Bartlett Learning.

Benton, T. H. (2003). The 5 virtues of successful graduate students. Chronicle of Higher Education, 50(2), C3-5. Retrieved from https://www.chronicle.com/

Bishop, J. (2016). An analysis of the implications of Maslow's hierarchy of needs for networked learning design and delivery. Proceedings of the International Conference on Information and Knowledge Engineering. Retrieved from https://www.researchgate.net/publication/307533183 An analysis of the implic ations of Maslow\%27s Hierarchy of Needs for networked learning design and deli very

Bulut, H., Hisar, F., \& Demir, S. G. (2010). Evaluation of mentorship programme in nursing education: A pilot study in Turkey. Nurse Education Today, 30(8), 756762. https://doi.org/10.1016/..nedt.2010.01.019

Commission on Accreditation in Physical Therapy Education. (2015). CAPTE accreditation handbook. Retrieved from http://www.capteonline.org/AccreditationHandbook/

Creswell, J. M., \& Creswell, J. D. (2017). Research design: Qualitative, quantitative, and mixed methods approaches (5th ed.). Washington DC: Sage Publishing.

Dickie, V. (2009). What is occupation? In Crepeau, E.B., Cohn, E.S., \& Boyt-Schell, B.A. (Eds.), Willard and Spackman's Occupational Therapy (11th ed., pp. 15-21). Baltimore, MD: Lippincott Williams \& Wilkins.

Evans, T. M., Bira, L., Gastelum, J. B., Weiss, L. T., \& Vanderford, N. L. (2018). Evidence for a mental health crisis in graduate education. Nature Biotechnology, 36(3), 282-284. https://doi.org/10.1038/nbt.4089

Ewles, G., Sorenson, J., \& Sasso, T. (2016). Hot topic or systemic issue? A closer look at graduate student health and well-being. The Industrial-Organizational Psychologist, 54(1), 1-5. Retrieved from http://my.siop.org/TIPdefault

Freitas, F. A., \& Leonard, L. J. (2011). Maslow's hierarchy of needs and student academic success. Teaching and Learning in Nursing, 6(1), 9-13. https://doi.org/10.1016/j.teln.2010.07.004 
Gobin, B. A., Teeroovengadum, V., Becceea, N. B., \& Teeroovengadum, V. (2012). Investigating into the relationship between the present level of tertiary students' needs relative to Maslow's hierarchy: A case study at the University of Mauritius. International Journal of Learning, 18(11), 204-219. Retrieved from http://www.commongroundpublishing.com/

Holdford, D., \& Lovelace-Elmore, B. (2001). Applying the principles of human motivation to pharmaceutical education. Journal of Pharmacy Teaching, 8(4), 1-18. https://doi.org/10.1300/j060v08n04 01

Jahan, F., Siddiqui, M. A., Mitwally, M., Al Zubidi, N. S. J., \& Al Zubidi, H. S. J. (2016). Perception of stress, anxiety, depression and coping strategies among medical students at Oman Medical College. Middle East Journal of Family Medicine, 14(7), 16-23. https://doi.org/10.5742/mewfm.2016.92856

Levecque, K., Anseel, F., De Beuckelaer, A., Vander der Heyden, J., \& Gisle, L. (2017). Work organization and mental health problems in $\mathrm{PhD}$ students. Research Policy, 46, 868-879. https://doi.org/10.1016/i.respol.2017.02.008

Maslow, A. H. (1954). Motivation and personality (3rd ed.). New York: Longman.

Maxwell, J. A. (2005). Qualitative research design: An interactive approach (2 ${ }^{\text {nd }}$ ed.). Thousand Oaks, CA: Sage.

Noltemeyer, A., Bush, K., Patton, J., \& Bergen, D. (2012). The relationship among deficiency needs and growth needs: An empirical investigation of Maslow's theory. Children and Youth Services Review, 34(9), 1862-1867. https://doi.org/10.1016/..childyouth.2012.05.021

Okahana, H., \& Zhou, E., (2017). Graduate enrollment and degrees: 2006 to 2016. Retrieved from https://cgsnet.org/ckfinder/userfiles/files/CGS GED16 Report Final.pdf

Oswalt, S. B., \& Riddock, C. C. (2007). What to do about being overwhelmed: Graduate students, stress, and university services. College Student Affairs Journal, 27(1), 24-44. Retrieved from http://www.sacsa.org/page/CSAJ

Panger, G., Tryon, J., \& Smith, A. (2014). The Graduate Assembly: Graduate student happiness \& well-being report. Retrieved from http://ga.berkeley.edu/wellbeingreport/

Patel, V. (2015, August 31). Grad schools try to ease 'culture problem' of anxiety and isolation. Chronicle of Higher Education, 62(1), 42. Retrieved from https://www.chronicle.com/

Pfeifer, T. A., Kranz, P. L., \& Scoggin, A. E. (2008). Perceived stress in occupational therapy students. Occupational Therapy International, 15(4), 221-231. https://doi.org/10.1002/oti.256

Saldana, J. (2016). The coding manual for qualitative researchers ( $3^{\text {rd }}$ ed.). London: Sage Publications.

Seegmiller, J. G., Nasypany, A., Kahanov, L., Seegmiller, J. A., \& Baker, R. (2015). Trends in doctoral education among healthcare professions: An integrative review. Athletic Training Education Journal, 10(1), 47-56. https://doi.org/10.4085/100147

Stubbs, J., Pyhältö, K., \& Lonka, K. (2012). The experienced meaning of working with a $\mathrm{PhD}$ thesis. Scandinavian Journal of Higher Education, 56(4), 439-456. https://doi.org/10.1080/00313831.2011.599422 
Wang, L. (2015). Opening up about stress in graduate school. Chemical and Engineering News, 93(36), 59-61. Retrieved from https://cen.acs.org/magazine/96/09608.html

Weidman, J. C., Twale, D. J., \& Stein, E. L. (2001). Socialization of graduate and professional student in higher education: A perilous passage. ASHE-ERIC Higher Education Report, 28(3). Retrieved from https://eric.ed.gov/?id=ED457710 